\title{
Libertad de prescripción médica
}

Alberto Lifshitz, Oscar Arrieta, Carlos Campillo, Rubén Burgos, Miguel Ángel Celis, Manuel De la Llata, Judith Domínguez, José Halabe, Sergio Islas, Luis Jasso, Mucio Moreno, Ricardo Plancarte, Alejandro Reyes-Sánchez, Guillermo Ruiz-Argüelles, Antonio Soda, Emma Verástegui y Julio Sotelo

Comité de Ética y Transparencia en la Relación Médico-Industria (CETREMI), Academia Nacional de Medicina de México, Ciudad de México, México

\section{Resumen}

Los médicos requieren flexibilidad para sus prescripciones. Sin embargo, algunos límites están marcados tanto por el conocimiento vigente como por las restricciones de acceso, normas y reglamentos. El Comité de Ética y Transparencia en la Relación Médico-Industria (CETREMI) propone varias sugerencias para ayudar a los pacientes, que incluyen la selección de las mejores alternativas para cada caso, la protocolización de variaciones a los estándares de prescripción (dosis, indicaciones, etcétera) por escrito en el expediente y eludir modas, novedades no probadas, argumentos simplemente publicitarios o promocionales y conflictos de interés.

PALABRAS CLAVE: Medicamentos. Prescripción. Terapéutica. Promoción de medicamentos. Cuadro básico.

\begin{abstract}
Doctors require flexibility for prescription. However, some limits are laid down both by current knowledge and by restrictions imposed by access and rules and regulations. The Committee for Ethics and Transparency in the Physician-Industry Relationship (CETREMI) of the National Academy of Medicine proposes several suggestions to help patients, which include the selection of the best alternatives for each case, formalization of prescription standards variations (doses, drug indications, etc.) written down in the medical records, and avoidance of fashions, untested novelties, argumentations solely based on advertising or commercial promotion and conflicts of interest.
\end{abstract}

KEY WORDS: Drugs. Prescription. Therapeutics. Drug promotion. Essential medicines list.

El médico es celoso de su libertad para tomar decisiones, asumiendo que las necesidades particulares de cada caso son únicas y solo él cuenta con los elementos para elegir la mejor opción. Se resiste a acatar regulaciones que pudieran acotar esta libertad. En tanto que la defensa de esta discrecionalidad tenga que ver con el bienestar de sus pacientes, bajo principios de beneficencia y autonomía, la libertad prescriptiva es legítima, no así cuando depende de defender una posición jerárquica arrogante o cuando responde a intereses diferentes que los de ofrecer la mejor alternativa al paciente.

Los límites de esta libertad están naturalmente definidos: por el conocimiento farmacológico, las peculiari- dades del paciente, las evidencias científicas, la existencia física de fármacos y tecnologías terapéuticas y el acceso a estas, que incluyen protocolos, normas y cuadros básicos de insumos. El acceso incluye costos y está acotado por las reglas de la prescripción, que debe ser racional (seleccionada mediante la razón), razonada (meditada, reflexionada), razonable (lógica, apropiada), racionada (sin dispendios) y racionalizada (justificada argumentativamente).

La concesión a priori a los médicos de confianza absoluta en su autoridad técnica y ética se ha confrontado con el hecho de que es un ser humano, con limitaciones derivadas de la complejidad de su oficio, la influencia de
Correspondencia:

Julio Sotelo

E-mail: jsotelo@unam.mx
Fecha de recepción: 12-02-2019

Fecha de aceptación: 19-02-2019

DOI:10.24875/GMM.19005082
Gac Med Mex. 2019;155:202-203

Disponible en PubMed

www.gacetamedicademexico.com 
su propia subjetividad, su impericia, los límites del conocimiento científico y la posibilidad de cometer errores involuntarios. En esta desmitificación influye el hecho de que muchos profesionales no poseen las cualidades técnicas y éticas que exige la profesión médica.

En la opinión del Comité de Ética y Transparencia en la Relación Médico-Industria (CETREMI) se enumeran recomendaciones en torno al ejercicio de la libertad prescriptiva:

1) Genéricos versus innovadores: la alternativa tiene que ver con costos, pero también con la confianza que tenga el médico hacia ciertos productos, derivada de experiencia, evidencias, compromisos o promoción eficaz. Conviene recordar que muchos genéricos se han sometido a pruebas de intercambiabilidad y se denominan genéricos intercambiables (GI) y que pueden sustituir confiadamente a los fármacos innovadores. La ventaja de menores costos compite con la desventaja de la desconfianza. Muchas instituciones han optado por utilizar genéricos intercambiables y los médicos que laboran para ellas se ven obligados a emplearlos. La farmacia no está autorizada a hacer sustituciones que no sean avaladas por los médicos.

2) Esquemas terapéuticos modificados: de acuerdo con las circunstancias y la experiencia propia, el médico puede proponer cambios en los esquemas terapéuticos convencionales, ya sea en dosis, vía de administración, fraccionamiento, combinaciones $u$ horarios. El tema es relevante ya que muchos cambios suelen carecer de sustento bibliográfico y pueden propiciar responsabilidades ante efectos adversos. Es recomendable que el médico se ajuste a los lineamientos documentados por la investigación.

3) Usos no validados o autorizados: varios medicamentos tienen propiedades adicionales a aquellas para los que fueron autorizados, se denominan efectos pleiotrópicos. Aquí también, para cualquier uso no validado o autorizado, se hace la misma sugerencia que en el inciso anterior: bajo protocolo, con metodología de investigación y con justificación razonable expresada en el expediente.

4) Selección de marcas comerciales: el médico tiene la libertad de elegir la especialidad farmacéutica. Los criterios para esta selección tienden a basarse en la familiaridad con el nombre, lo cual suele derivar de la publicidad que haya hecho el productor. $\mathrm{Si}$ se elige prescribir por principio activo, la selección de una marca la ejerce el dependiente de la farmacia, que puede obedecer a incentivos comerciales.

5) Veto de productos: ha ocurrido que, por razones comerciales o de relaciones interpersonales, algunos colegas han vetado una cierta marca comercial. Aunque esto va dentro de la libertad de elegir, CETREMI ya se pronunció al respecto descalificando esta forma de proceder, sobre todo cuando se trata de cuerpos colegiados. Las agencias regulatorias son las que pueden emitir alertas 0 retirar del mercado productos inconvenientes para la salud.

6) Seguimiento de normas, guías, algoritmos y consensos: salvo ciertas normas obligatorias, estos documentos son orientaciones que ayudan en las decisiones y es potestad de los profesionales acatarlas o no. Cuando se decide no seguirlas, la recomendación es argumentar en el expediente las razones.

7) Cuadros básicos: son instrumentos para el control administrativo de insumos para la salud. Generalmente son suficientemente amplios para cubrir la mayoría de las necesidades terapéuticas, de modo que es preferible hacer una selección de entre lo enlistado en ellos, sin embargo, debe existir flexibilidad para que se admitan excepciones justificadas.

8) Interacciones: la previsión de interacciones es una condición elemental que debe orientar la prescripción.

9) Costos: es una limitante ética a la libertad de prescripción. Las decisiones terapéuticas tienen que ser matizadas tomando en cuenta los costos, de modo que en igualdad de circunstancias se debe elegir lo menos costoso.

10) Modas y tendencias: es frecuente que con estrategias publicitarias se genere la moda de utilizar un determinado medicamento. Habrá que considerar que no siempre lo nuevo es lo mejor, o que lo más caro es lo mejor, o que lo mejor publicitado es lo mejor, o que lo inyectado es lo mejor.

11) No medicación: si el padecimiento se puede manejar exclusivamente con otras recomendaciones, terminar una consulta médica sin prescripción medicamentosa representa una situación favorable, en tanto que se evitan los riesgos asociados con medicamentos.

12) Rutinas, decisiones instintivas, insistencia de pacientes o familiares, complacencias o práctica defensiva: aunque pudieran formar parte de la libertad prescriptiva, la recomendación es eludirlas. 